\title{
Thermal Errors Classification Compensation without Sensor for CNC Machine Tools
}

\author{
Xian Wei $\mathbb{D}^{1,2}$ Feng Gao $\mathbb{D}^{1},{ }^{1}$ Yan Li, ${ }^{1}$ and Dongya Zhang ${ }^{1}$ \\ ${ }^{1}$ Xi'an University of Technology, Key Lab. of NC Machine Tools and Integrated Manufacturing Equipment of the Education \\ Ministry \& Key Lab of Manufacturing Equipment of Shaanxi Province, No. 5 Jinhua South Road, Xian 710048, China \\ ${ }^{2}$ School of Transportation \& Automotive Engineering, Panzhihua University, No. 5 Airport Road, Panzhihua 617000, China \\ Correspondence should be addressed to Feng Gao; gf2713@126.com
}

Received 10 April 2018; Revised 16 July 2018; Accepted 30 July 2018; Published 16 August 2018

Academic Editor: R Aguilar-López

Copyright (C) 2018 Xian Wei et al. This is an open access article distributed under the Creative Commons Attribution License, which permits unrestricted use, distribution, and reproduction in any medium, provided the original work is properly cited.

\begin{abstract}
Both multicollinearity and utilization deficiency of temperature sensors affect the robustness and the prediction precision of traditional thermal error prediction models. To address the problem, a thermal error prediction model without temperature sensors is proposed. Firstly, the paper analyzes the temperature field and thermal deformation mechanisms of the spindle of a CNC gear grinding machine in accordance with the parameters, efficiencies, and structures of the machine spindle and bearing. A preliminary theoretical model is established on the basis of the mechanism analysis. Secondly, the theoretical model is corrected according to the actual operation parameters of the machine. Thirdly, verification experiments are carried out on machine tools of the same type. It is found that the corrected model has higher precision in predicting thermal errors at the same rotational velocity. The standard deviation and the maximum residual error are reduced by at least $39 \%$ and $48 \%$ separately. The prediction precision decreases with the increase in prediction range when predicting thermal errors at different rotational velocities. The model has high prediction precision and strong robustness in the case of reasonable prediction range and classified prediction. In a word, prediction precision and robustness of the model without temperature sensors can be effectively ensured by reasonably determining the prediction range and practicing classified prediction and compensation for thermal errors at different rotational velocities. The model established can be applied to machine tools that have difficulties in arranging sensors or those whose sensors are significantly disturbed.
\end{abstract}

\section{Introduction}

Thermal errors, which have become one of the major impact factors on component manufacturing precision in CNC precision machining, account for $50 \sim 70 \%$ of all manufacturing errors $[1,2]$. Currently, there are many methods of reducing the impact of thermal errors, including symmetric structural design, use of materials with low thermal expansion coefficient, workplace temperature control, and thermal error compensation [3]. Among them, thermal error compensation has been widely used to compensate thermal errors of the various machine tools due to its economic efficiency $[4,5]$.

The core problem of thermal error compensation is to establish a mathematical model that has high prediction precision and strong robustness. Generally, thermal error compensation follows the steps below. (1) Appropriate temperature measurement points are selected. (2) A thermal error compensation model is established on the basis of the temperature data collected. (3) Thermal errors are predicted in real time. Jiri Vyroubal [6] divided machine tools into several parts and arranged temperature sensors in each part. An error prediction model was built on the premise of finding temperature-sensitive points most relevant to thermal errors through correlation analysis. Lee et al. [7] organically combined linear regression with correlation analysis to optimize temperature-sensitive points and considered the minimum sum of residual squares as the basis for selecting temperaturesensitive points. Yang et al. [8, 9] screened five temperaturesensitive points with the highest grey correlation degree by computing the grey correlation between thermal errors and temperature sensors, thereby achieving the goal of optimization. However, all these methods caused multicollinearity among the measurement points selected, eventually leading to the poor robustness of error compensation models 
[10]. To eliminate the impact of multicollinearity among temperature-sensitive points, Miao et al. [11, 12] employed principle component regression analysis to optimize the modeling variables. All of the above methods collect temperature information through temperature sensors. Sensors, as the major information detection devices, are mostly challenged by temperature coefficient differences, nonlinear response curves, slow responses, and cross-sensitivity [13]. In the meantime, many industrial processes are characterized by multiple variables, strong interference, hysteresis, and strong coupling, which shall inevitably result in some sensor prediction errors. Therefore, some scholars [14-16] analyzed the temperature field of machine tools by using finite element analysis, so as to avoid the impact of sensors on the prediction precision. Kim [17] used the finite element method to establish temperature field models for ball screws at different feeding velocities. Nevertheless, the models were inaccurate since the temperature of ball screws was assumed to be consistent. Ming [18] established temperature models for ball screws by using finite element analysis and took into account the thermal contact resistance of bearings. Horejs [19] adopted the closed-loop finite element method for ball screw analysis and verified the impact of screw load on the stability of ball screws. Li [20] established thermal error prediction models by using the multivariate method, so as to improve the robustness of the prediction models that took temperature as the input variable. However, it is a complicated process to determine the variable. Bossmanns [21] used the finite difference method to characterize the temperature distribution of motor spindle. Shi [22] constructed axial heat generation equations by analyzing the heat generation and heat transfer of ball screws. Nevertheless, further application of the method is limited by the uncertain boundary conditions in finite element analysis.

To address the above problems a thermal error compensation model without temperature sensors is proposed in this paper. The theoretical prediction models for temperature field and thermal deformation are established based on the mechanism analysis of the spindle of a CNC gear grinding machine (YKZ7230). The paper simulates actual operation conditions of the spindle and corrects the theoretical model in accordance with the temperature and thermal deformation data collected, thereby obtaining a mathematical model that is consistent with the actual situation. Considering that acquisition of the corrected data is influenced by working environments, necessary measures are taken to minimize the impact of environmental factors on sensors, so as to ensure the modeling precision. The sensorless prediction of thermal errors has the following advantages: (1) economically efficient: no additional data acquisition devices or detection sensors are required; (2) convenient: there is no need for online real time sensor monitoring; (3) robust: the sensorless prediction eliminates errors caused by sensor instability and external interference. In the meantime, the impact of multicollinearity caused by improper measurement points is eliminated.

Contributions of this paper lie in the following two aspects: (1) different from the traditional thermal error model, the model proposed in this paper has no temperature sensors; therefore, it eliminates the interference errors caused

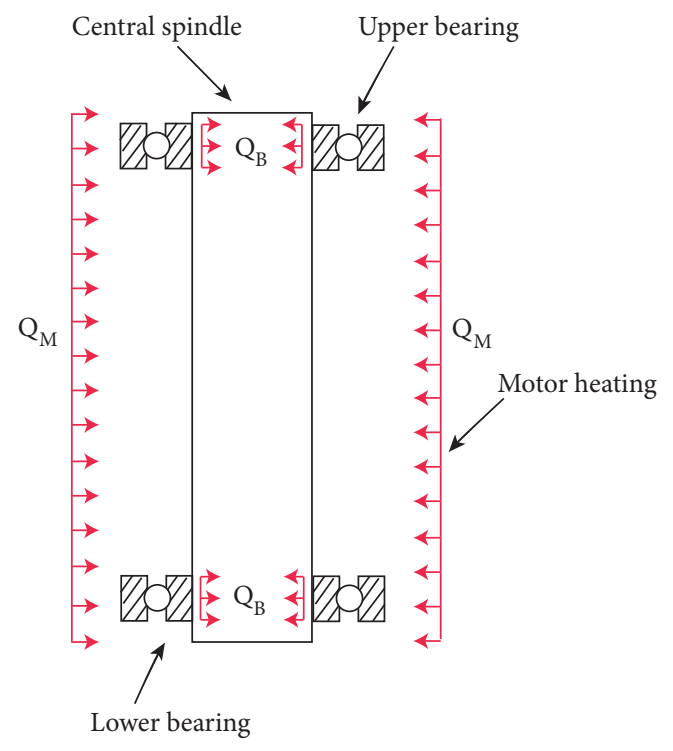

FIGURE 1: Schematic of heat generation of a spindle.

by temperature sensors, thereby improving the prediction precision and robustness; (2) thermal errors are influenced by multiple parameters, including thermal contact resistance, ambient temperature, spindle velocity, and hysteresis. As a result, the unified thermal error model has poor robustness. The experimental results show that classified prediction [23] can effectively improve the prediction precision and robustness.

\section{Establishment of the Sensorless Models}

2.1. Theoretical Model for Temperature Field. Spindle is a major supporting component of the gears of CNC gear grinding machines. Therefore, thermal errors caused by spindle motor heating and bearing heating shall inevitably exert a significant impact on the gear machining quality.

2.1.1. Spindle Heat Generation. As is shown in Figure 1, spindle heat generation mainly consists of motor heat generation and bearing heat generation. Heat generated by the motor can be calculated in accordance with the motor efficiency while heat generated by the bearings mainly comes from friction.

Therefore, the motor heat is expressed as

$$
Q_{M}=Q_{M-\text { in }}-Q_{M-o u t}
$$

where $Q_{M}$ is the heat generated by the spindle; $Q_{M \text {-in }}$ is the energy input into the spindle and can be calculated from the input voltage and current of the motor; $Q_{M \text {-out }}$ is the mechanical energy output and expressed by torque and rotational velocity. The calculation parameters in (1) are easily obtained.

According to Document [24], frictional heat of the bearings can be expressed as

$$
Q_{B}=1.047 \times 10^{-4} n M
$$

where $Q_{B}$ is the heat generated by the gearings; $n$ is the spindle velocity; $M$ is the total frictional moment of the bearings. 
The overall heat equation of the spindle is expressed as

$$
Q_{\text {in }}=Q_{M}+Q_{B 1}+Q_{B 2}
$$

where $Q_{i n}$ is the total heat input into the spindle; $Q_{B 1}$ is the heat generated by the upper bearing; $Q_{B 2}$ is the heat generated by the lower bearing.

2.1.2. Basic Theoretical Model for Temperature Field. Equation (4) can be constructed based on the heat input and output of the spindle [25]:

$$
\begin{aligned}
c m\left(\frac{d T_{m}}{d t}\right) & =Q_{\text {in }}-Q_{\text {out }} \\
Q_{\text {out }} & =T_{m} S \alpha
\end{aligned}
$$

where $c$ is the specific heat capacity of the spindle materials; $m$ is the spindle mass; $T_{m}$ is the spindle temperature; $S$ is the heat radiation area of the spindle; $\alpha$ is the thermal diffusion coefficient of the spindle; $Q_{\text {out }}$ is the heat dissipation of the spindle.

Based on (4) and (5), average temperature $T_{m}$ and time constant $t_{c}$ of the spindle can be expressed as

$$
\begin{aligned}
T_{m} & =\frac{Q_{\text {in }}}{(S \alpha)}+B \exp \left(\frac{-t}{t_{c}}\right) \\
t_{c} & =\frac{c m}{(S \alpha)}
\end{aligned}
$$

where $B$ is the coefficient determined by the initial ambient temperature.

2.1.3. Theoretical Model for Spindle Heating. The spindle is heated during rotation, leading to forced convection between the spindle and the air. The forced convection coefficient $\alpha_{u p}$ can be expressed as

$$
\alpha_{u p}=0.664 \lambda\left(\frac{n}{60 v h_{p}}\right)^{1 / 2} p_{r}^{1 / 3}
$$

where $\lambda$ is the thermal conductivity coefficient of the spindle; $n$ is the spindle velocity; $v$ is the kinematic viscosity of air $\left(v=16 \mathrm{~mm}^{2} / \mathrm{s}\right) ; h_{p}$ is the experimental coefficient that is adjusted in accordance with specific experimental conditions; $p_{r}$ is the Prandtl constant $\left(p_{r}=0.701\right)$.

Theoretical model for the spindle temperature field in the warming process can be obtained by substituting $\alpha_{u p}$ and (7) into (6).

$$
T_{u p}=\frac{Q_{i n}}{\left(S \alpha_{u p}\right)}+B \exp \left(\frac{-\alpha_{u p} S t}{m c}\right)
$$

2.1.4. Theoretical Model for Spindle Cooling. The spindle conducts natural convection heat transfer to air when it stops rotating. The natural convection coefficient $\alpha_{\text {down }}=10 \mathrm{~W} /\left(\mathrm{m}^{2} \cdot \mathrm{K}\right)$ and the heat input $Q_{\text {in }}=0$. Therefore,

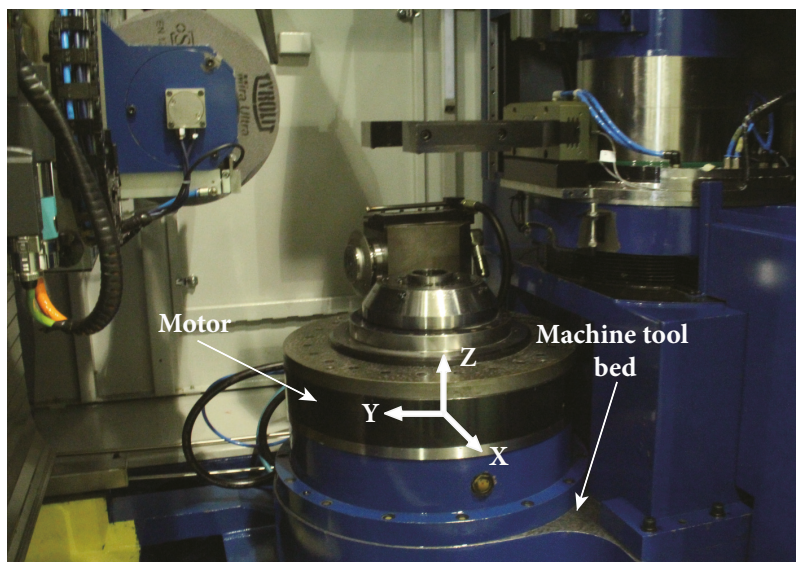

FIgURE 2: Structure of the machine tools.

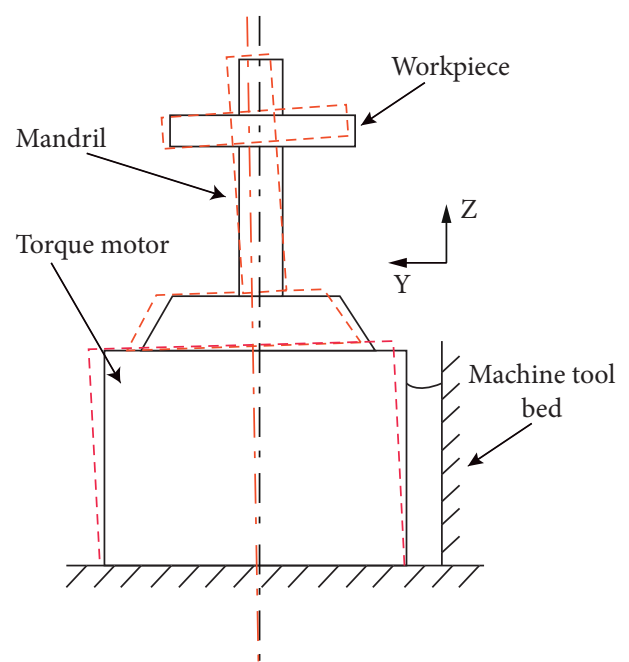

FIgURE 3: Thermal deformation of the spindle.

theoretical model for the spindle temperature field in the cooling process can be expressed as

$$
T_{\text {down }}=T_{0} \exp \left(\frac{-10 S t}{m c}\right)
$$

where $T_{0}$ is the initial temperature of the cooling phase.

\subsection{Thermal Deformation Model}

2.2.1. Theoretical Model for Thermal Deformation. To establish the theoretical model for thermal deformation, it is necessary to analyze the structure and deformation characteristics of the gear grinding machine first. The structure of the machine tool is shown in Figure 2. According to the thermal deformation theory, the machine tool is structurally symmetric in the $\mathrm{X}$ direction, which has little impact on thermal deformation of the spindle. Due to the asymmetric structure in the Y direction, the spindle shall bend in the Y direction and the basement shall tilt during heating. Deformation in the $\mathrm{Z}$ direction mainly refers to spindle thermal extension. Figure 3 demonstrates thermal deformation of the spindle. 


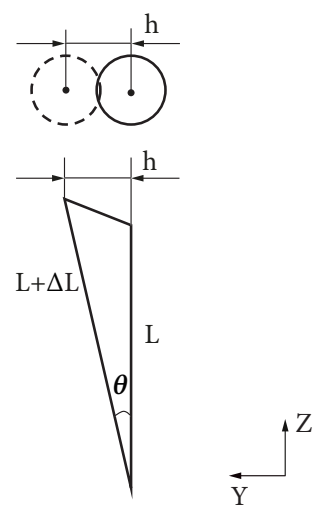

FIGURE 4: An abbreviated drawing of spindle thermal deformation.

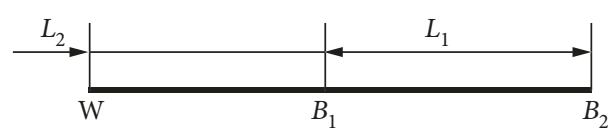

FIgURe 5: A structural diagram of the spindle.

Figure 4 is an abbreviated drawing of the thermal deformation in Figure 3.

As is shown in Figure 4, major errors that influence the component precision mainly consist of two parts: errors caused by the spindle inclination angle $\theta$ in the $\mathrm{Y}$ direction $(h)$ and errors caused by spindle thermal extension in the $\mathrm{Z}$ direction $(\Delta L)$. Therefore, thermal errors can be expressed with $h$ and $\Delta L$. Expressions of thermal errors are described below:

(1) Theoretical Formula of $\Delta L$. Considering the structure of the machine tools, the spindle is divided into two parts when calculating $\Delta L$, as shown in Figure 5.

$B_{1} B_{2}$, which represents the distance between the upper and lower bearings of the spindle, is expressed by $L_{1}$. $\mathrm{WB}_{1}$, which represents the distance between the upper bearing and the mandrel, is expressed by $L_{2}$. $B_{1}$ is fixed while $B_{2}$ is mobile, indicating that thermal extension in $\mathrm{B}_{1} \mathrm{~B}_{2}$ has no impact on thermal errors. $\mathrm{WB}_{1}$ experiences single point heating, with $B_{1}$ as the heated point. Since thermal deformation that takes place in $\mathrm{WB}_{1}$ influences the precision of machine tools, $\Delta L_{2}=\Delta L$. According to Document [26], the temperature is triangularly distributed in $\mathrm{WB}_{1}$ (see Figure 6). The thermal extension $\Delta L_{2}$ is expressed as

$$
\Delta L_{2}=\alpha_{t} \int_{0}^{L_{2}} T(x) d x
$$

Equation (12) is obtained by substituting $T(x)=$ $T_{\max }\left(x / L_{2}\right)$ into (11).

$$
\Delta L_{2}=\alpha_{t} \int_{0}^{L_{2}} T_{\max } \frac{x}{L_{2}} d x=\frac{\alpha_{t} L_{2} T_{\max }}{2}=\frac{\alpha_{t} L_{2} T_{\mathrm{m}}}{2}
$$

where $\alpha_{t}$ is the linear expansion coefficient of materials; $T_{\max }$ is the temperature at $\mathrm{B}_{1} \cdot T_{\max }=T_{u p}=T_{\mathrm{m}}$ during warming and

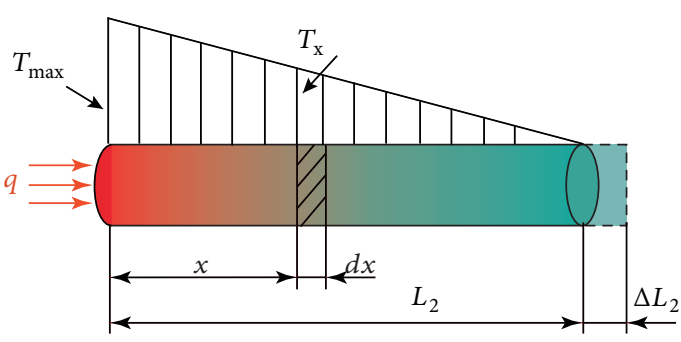

FIgURE 6: Triangular temperature distribution.

$T_{\max }=T_{\text {down }}=T_{\mathrm{m}}$ during cooling. $T_{\max }$ can be obtained by (9) and (10).

(2) Theoretical Equation of $h$. According to Figure 4, the following can be obtained:

$$
h=(L+\Delta L) \sin \theta
$$

where $\theta$ is a function that varies with temperature. Since $\theta$ is small, it can be expressed as

$$
\theta=\beta T_{m}
$$

Since $\Delta L$ is far smaller than $L$, it can be neglected. Substituting (14) into (13), the thermal error $h$ can be eventually expressed as

$$
h=L \sin \left(\beta T_{m}\right)
$$

where $\beta$ is the undetermined coefficient. According to practical machining experience, $h$ is small and easily calculated. Therefore, it is feasible to directly determine $\beta$ on the basis of experimental data, thereby obtaining prediction equations consistent with the actual conditions.

\subsection{Correction of the Temperature and Thermal Deformation Models}

2.3.1. Correction of the Temperature Model. In the following sections, the temperature model correction process is illustrated by the example of the spindle.

The spindle rotates at a constant velocity during machining, leading to an increase in temperature. It stops rotating when the machining is completed and the temperature drops accordingly in that case. The theoretical and actual temperature curves of the machine tools during operation are shown in Figure 7. It is revealed in the figure that the theoretical curve deviates from the actual curve. Therefore, the correction of the theoretical curve is the key to ensure the prediction precision and robustness of the model.

(1) Correction of the Model during Heating. Equation (9) can be corrected as follows in accordance with the experimental data:

$$
T_{u p}=T_{e}+\frac{Q_{i n}}{\left(S \alpha_{u p}\right)}+B \exp \left(\frac{-p_{u p 1} \alpha_{u p} S t}{m c}\right)+p_{u p 2}
$$




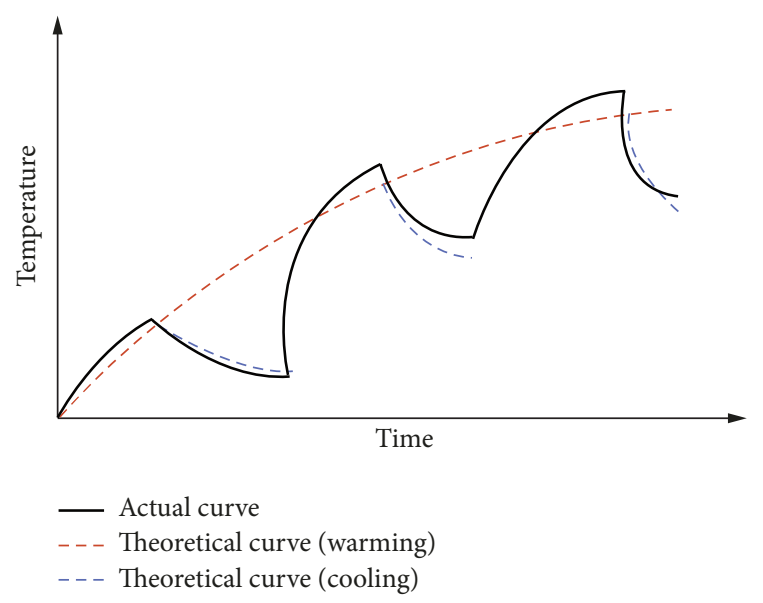

Figure 7: Schematic drawing of the theoretical and actual temperature curves.

where $T_{e}$ is the ambient temperature; $p_{u p 1}$ is the correction slope during heating; $p_{u p 2}$ is the temperature correction value during heating.

The optimal correction coefficients $T_{e}, p_{u p 1}$, and $p_{u p 2}$ can be obtained by solving the optimal solution of the objective function. The objective function during heating can be established in accordance with Document [25].

(2) Correction of the Model during Cooling. Similarly, (10) can be corrected as

$$
T_{\text {down }}=T_{e}+\left(T_{0}-T_{e}\right) \exp \left(\frac{-p_{d n 1} 10 S t}{m c}\right)+p_{d n 2}
$$

where $p_{d n 1}$ is the correction slope during the $n^{\text {th }}$ cooling process and $p_{d n 2}$ is the temperature correction value during the $n^{\text {th }}$ cooling process.

2.3.2. Correction of the Thermal Error Model. The thermal error model is corrected in a similar way to the temperature model. The thermal error model during heating is corrected in accordance with (12) as

$$
\Delta L_{2}=p_{1} \frac{\alpha_{t} L_{2} T_{\max }}{2}+p_{2}
$$

where $p_{1}$ is the correction slope of thermal errors and $p_{2}$ is the correction value of thermal errors.

The optimal correction coefficients $p_{1}$ and $p_{2}$ can be obtained by solving the optimization problem.

\section{Experimental System}

3.1. Experimental Equipment. According to the theoretical analysis in previous chapters, it is necessary to correct the theoretical models in accordance with the temperature and thermal deformation data acquired. The experiment takes YKZ7230 (a CNC gear grinding machine) as the experimental platform and uses HIOKI8423 as the data acquisition instrument. The temperature and displacement

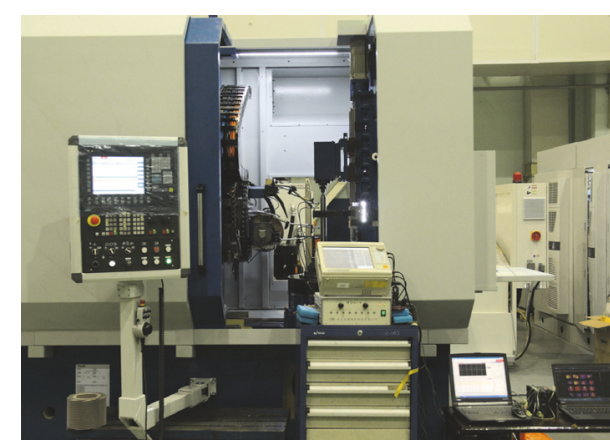

FIGURE 8: Experimental system.

sensors adopted are E-type MG-24E-GW1-ANP (a temperature sensor manufactured by Anritsu Meter) and DGC8ZG/D (a noncontact displacement sensor manufactured by Zhongyuan Measuring) separately. The experimental system is shown in Figure 8.

3.2. Experimental Design. In accordance with the international standard Test Code for Machine Tools-Part 3: Determination of Thermal Effects (IS0 230-3:2001 IDT) [27], all the experiments were carried out at a constant temperature of $20^{\circ} \mathrm{C}$. It should be noted that the spindle was in an idling condition. The spindle shall stop rotating when machine tools replace workpieces and repair grinding wheels during actual machining, leading to a decline in spindle temperature. Therefore, the heating and cooling cycles were set to 20 minutes and 5 minutes separately. And the cycles were repeated until the temperature reached thermal equilibrium.

To avoid the impact of sensor defects on the model proposed, the following measures were taken:

(1) To ensure the precision of the temperature and thermal deformation data measured, shielding tubes were introduced to protect sensor cables during data acquisition. In the meantime, surrounding machine tools and other devices were disabled to avoid interference in the experimental data. The gross-error data was eliminated.

(2) Sensors were wrapped in plastic films during the experiments, so as to minimize the impact of cutting fluids on the model.

(3) Considering the impact of the multicollinearity of temperature sensors, 4 temperature sensors were evenly arranged around the measured object during model correction. Average temperature of the 4 temperature sensors was calculated and used as the temperature of the model, thereby avoiding the impact of multicollinearity on the model proposed.

Considering the changes of temperature fields and thermal errors with rotational velocity, experiments were carried out at different spindle velocities. Since the rotational velocity of YKZ7230 ranges between 0 and $300 \mathrm{r} / \mathrm{min}$, the experimental rotational velocities are evenly distributed in this range. The grouping of the experimental rotational velocities is shown in Table 1.

3.2.1. Temperature Data Acquisition. In order to accurately arrange the temperature sensors, FLIR infrared camera was 


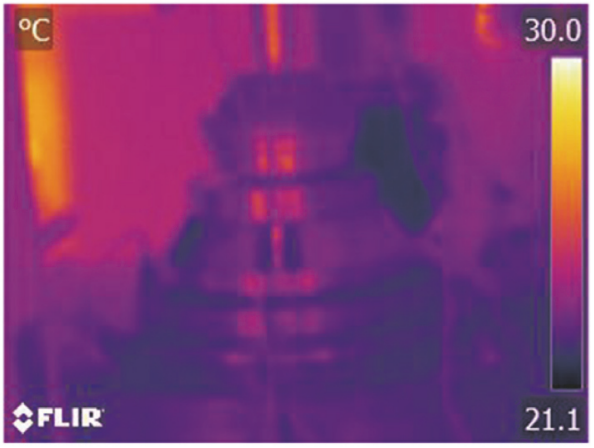

(a)

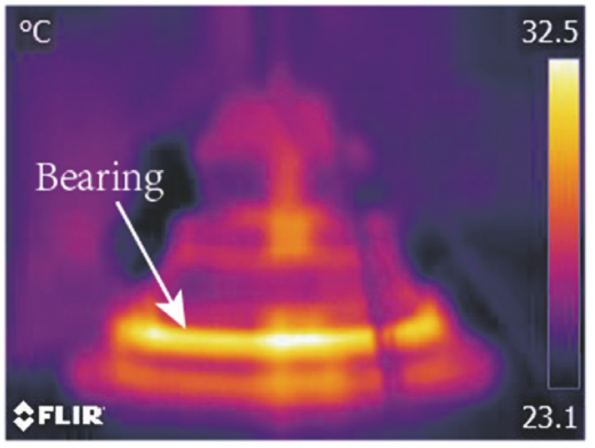

(b)

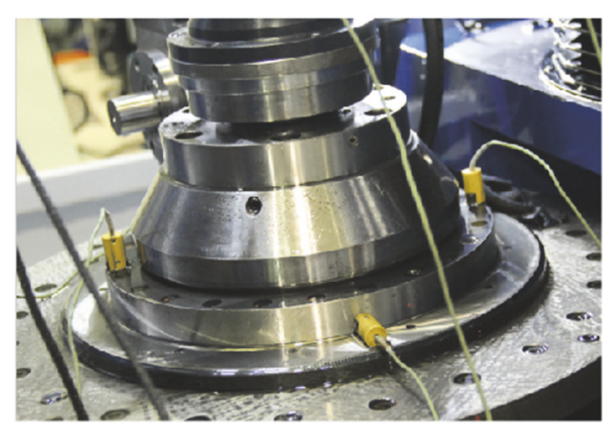

(c)

FIGURE 9: Infrared image of the spindle and arrangement of the temperature sensors. (a) Before heating. (b) After heating. (c) Arrangement of the temperature sensors.

TABLE 1: Experimental rotational velocity.

\begin{tabular}{lccc}
\hline Category & Velocity $(\mathrm{r} / \mathrm{min})$ & Category & Velocity $(\mathrm{r} / \mathrm{min})$ \\
\hline 1 & 30 & 6 & 180 \\
2 & 60 & 7 & 210 \\
3 & 90 & 8 & 240 \\
4 & 120 & 9 & 270 \\
5 & 150 & 10 & 300 \\
\hline
\end{tabular}

employed to capture the central spindle and seek major heat sources. The thermal image is shown in Figures 9(a) and 9(b). It is revealed in Figure 9(b) that the main heating component is the bearing. To acquire temperature data more uniformly, 4 temperature sensors were uniformly arranged in the circumference near the bearing, as shown in Figure 9(c). We computed average temperature of the 4 temperature sensors and obtained 10 sets of temperature data under different rotational velocities. The actual temperature curve measured is shown in Figure 10. As Figure 10 shows, temperature of the spindle bearing increases with the increase in spindle velocity and drops quickly when the spindle stops rotating. $T_{\text {up }}$ and $T_{\text {down }}$ in (16) and (17) can be corrected by virtue of the actual temperature data.

3.2.2. Acquisition of Thermal Deformation Data. Thermal deformation of the spindle mainly takes place in the Y direction and the $\mathrm{Z}$ direction. Therefore, the displacement sensors S1 and S2 are arranged as in Figure 11. The deformation angle

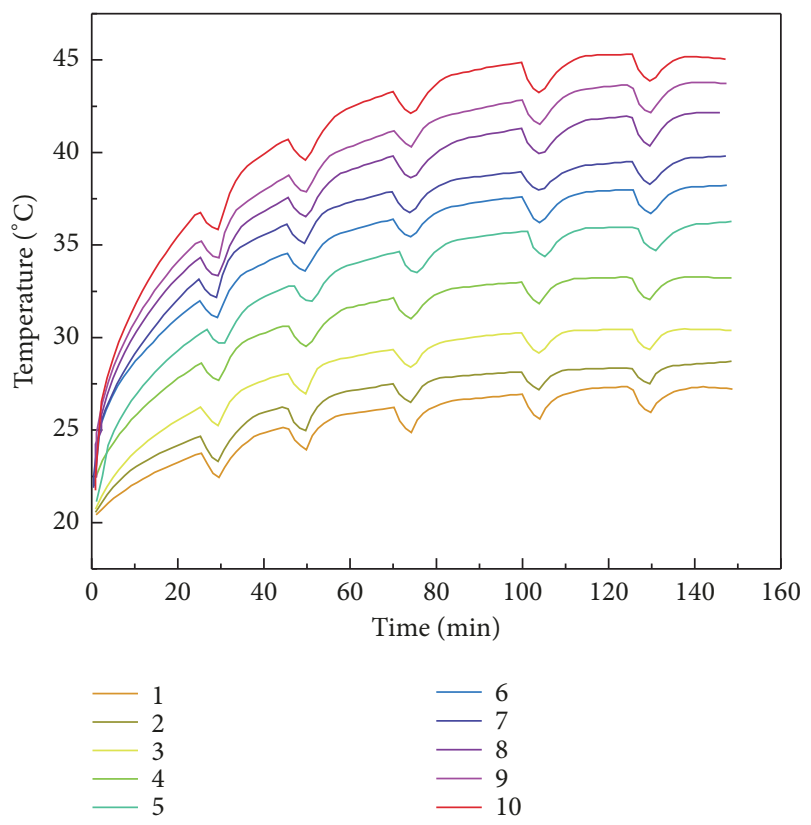

FIGURE 10: Experimental temperature curves.

$\theta$ in Figure 4 can be obtained by calculation, based on which the actual thermal deformation in the $\mathrm{Y}$ direction $(h)$ can be obtained. The displacement sensor S3 in Figure 11 is used to measure actual deformation in the $\mathrm{Z}$ direction, namely, $\Delta L$. 
TABLE 2: Spindle parameters.

\begin{tabular}{lcc}
\hline Parameters & Units & Value \\
\hline Spindle diameter & $\mathrm{D}(\mathrm{mm})$ & 105 \\
Spindle bore & $\mathrm{D}_{K}(\mathrm{~mm})$ & 75 \\
Spindle length & $\mathrm{L}(\mathrm{mm})$ & 260 \\
Spindle density & $\rho\left(\mathrm{kg} / \mathrm{m}^{2}\right)$ & $7.6 \times 10^{3}$ \\
specific heat capacity & $\mathrm{c}(\mathrm{J} /(\mathrm{kg} \cdot \mathrm{k}))$ & 460 \\
Linear expansion coefficient & $\alpha_{t}(1 / \mathrm{k})$ & $1 \times 10^{-5}$ \\
Thermal conductivity & $\lambda(\mathrm{W} /(\mathrm{m} \cdot \mathrm{k}))$ & 31.2 \\
\hline
\end{tabular}

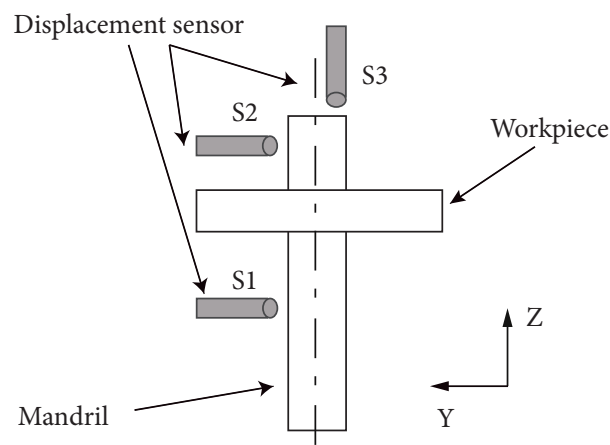

FIGURE 11: Arrangement of displacement sensors.

\section{Result Verification}

4.1. Correction Model. Table 2 demonstrates parameters of the machine spindle. Correction coefficients of the temperature field and thermal deformation models at different rotational velocities can be obtained by virtue of the methods introduced in Section 2, as shown in Tables 3 and 4 separately. Since the experiments were carried out at a constant temperature, $T_{e}$ in (16) and (17) is equal to the ambient temperature, namely, $T_{\mathrm{e}}=20^{\circ} \mathrm{C}$.

4.2. Model Prediction Result before and after Correction. To illustrate the effect of the modified model, one of these models is used as an example to discuss.

Figure 12 is a comparison of the prediction results between the theoretical prediction model for temperature and the corrected model when the spindle velocity is $240 \mathrm{r} / \mathrm{min}$. According to the figure, the corrected model is far superior in prediction precision, indicating the feasibility of temperature correction.

Figure 13 is a comparison of the prediction results between the theoretical model for $\triangle L$ and the corrected model when the spindle velocity is $240 \mathrm{r} / \mathrm{min}$. It is revealed in the figure that prediction results of the theoretical model fluctuate significantly with temperature changes during spindle cooling. Influenced by the thermal contact resistance and machine tool structure, the actual measurement curve is insensitive to the drastic temperature changes. Overall, the corrected model obtains good prediction results.

Table 5 is a numerical comparison of the prediction results between the theoretical prediction model for $\triangle L$ and the corrected model when the spindle velocity is $240 \mathrm{r} / \mathrm{min}$.

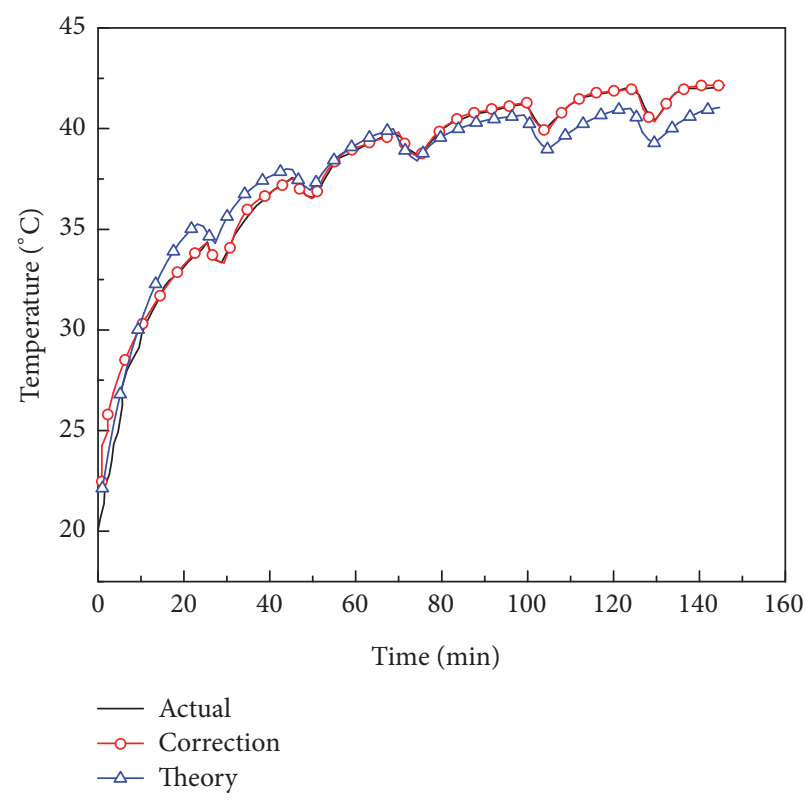

FIGURE 12: Comparison of temperature curves before and after correction.

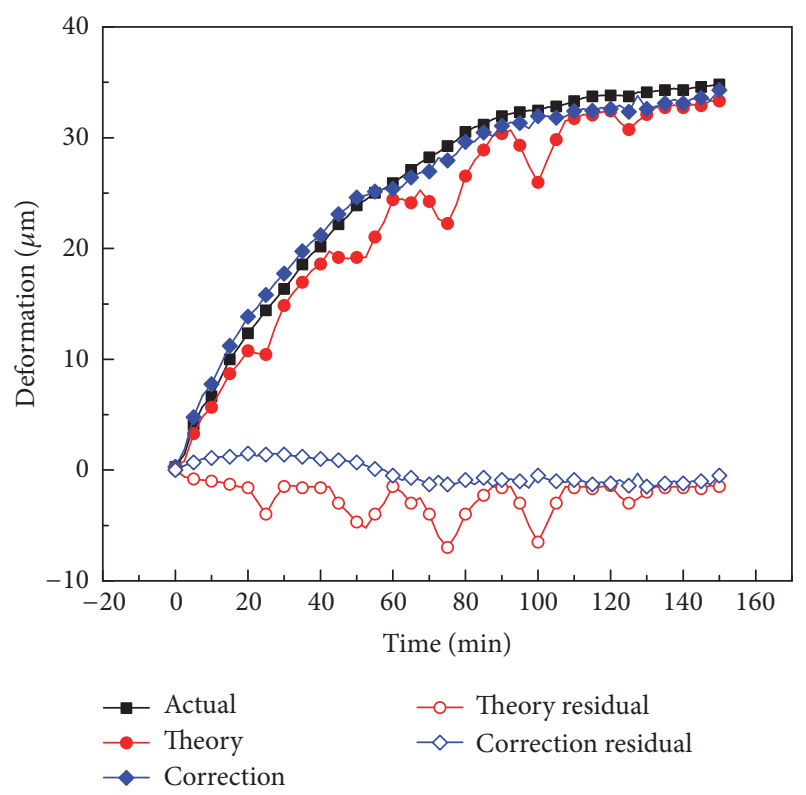

FIGURE 13: Comparison of $\triangle L$ before and after correction.

As the figure shows, the prediction precision is significantly improved after correction. The standard deviation and the maximum residual are reduced by $60 \%$ and $79 \%$ separately.

Figure 14 is a comparison of the prediction results between the theoretical prediction model for $h$ and the corrected model when the spindle velocity is $240 \mathrm{r} / \mathrm{min}$. It can be seen from the figure that the corrected model has better prediction results than the theoretical model.

Table 6 is a numerical comparison of the prediction results between the theoretical prediction model for $h$ and the corrected model when the spindle velocity is $240 \mathrm{r} / \mathrm{min}$. 
TABLE 3: Correction coefficient of the temperature field model.

\begin{tabular}{|c|c|c|c|c|c|c|c|c|c|c|c|c|}
\hline \multirow{2}{*}{ Velocity (r/min) } & \multicolumn{12}{|c|}{ Coefficient } \\
\hline & $P_{\text {up1 }}$ & $P_{\text {up2 }}$ & $P_{\mathrm{d} 11}$ & $\mathrm{P}_{\mathrm{d} 12}$ & $P_{\mathrm{d} 21}$ & $P_{\mathrm{d} 22}$ & $P_{\mathrm{d} 31}$ & $P_{\mathrm{d} 32}$ & $P_{\mathrm{d} 41}$ & $P_{\mathrm{d} 42}$ & $P_{\mathrm{d} 51}$ & $P_{\mathrm{d} 52}$ \\
\hline 30 & 0.72 & 1.89 & 1.53 & 1.23 & 0.92 & 1.58 & 1.93 & -2.1 & 1.34 & 1.15 & 1.26 & 1.14 \\
\hline 60 & 0.96 & 2.03 & 1.32 & -0.5 & 1.52 & 2.3 & 1.41 & 1.77 & 1.62 & 1.9 & 1.75 & 1.73 \\
\hline 90 & 1.05 & 1.71 & 1.47 & 1.56 & 1.43 & -0.9 & 1.27 & 1.43 & 1.36 & 1.46 & 1.04 & 1.38 \\
\hline 120 & 1.16 & 1.83 & 0.97 & -2.7 & 1.29 & 1.8 & 1.53 & -1.8 & 1.56 & -0.3 & 1.97 & 1.47 \\
\hline 150 & 1.21 & 1.9 & 1.23 & 1.91 & 1.34 & 3.2 & 1.36 & -0.9 & 1.8 & -0.5 & 2.1 & 1.6 \\
\hline 180 & 1.25 & 1.74 & 1.46 & 1.75 & 1.09 & 0.95 & 1.17 & 1.5 & 0.96 & 1.64 & 1.37 & -2.3 \\
\hline 210 & 1.34 & -0.3 & 0.98 & 0.83 & 0.96 & 2.1 & 1.04 & 1.27 & 1.23 & 1.3 & 1.42 & -1.1 \\
\hline 240 & 1.38 & 0.64 & 1.12 & 0.97 & 0.78 & 1.55 & 0.95 & -1.7 & 1.53 & -1.5 & 1.54 & 2.41 \\
\hline 270 & 1.43 & 0.79 & 1.08 & -2.1 & 0.93 & 1.85 & 0.91 & -1.1 & 1.79 & 1.33 & 1.69 & -3.7 \\
\hline 300 & 1.49 & 0.62 & 1.05 & -1 & 1.93 & 1.42 & 1.12 & 2.7 & 1.02 & 1.39 & 1.72 & -1.1 \\
\hline
\end{tabular}

TABLE 4: Correction coefficients of the thermal deformation model.

\begin{tabular}{lccc}
\hline Velocity (r/min) & \multicolumn{3}{c}{ Coefficient } \\
\hline 30 & $P_{1}$ & $P_{2}$ & $\beta$ \\
60 & 1.43 & -0.79 & 0.065 \\
90 & 1.37 & -0.87 & 0.063 \\
120 & 1.33 & -0.54 & 0.059 \\
150 & 1.34 & -0.72 & 0.052 \\
180 & 1.29 & -0.62 & 0.049 \\
210 & 1.26 & -0.31 & 0.046 \\
240 & 1.2 & 0.15 & 0.044 \\
260 & 1.13 & 0.24 & 0.041 \\
300 & 1.09 & -0.42 & 0.04 \\
\hline
\end{tabular}

TABLE 5: Prediction results of $\triangle L$ (unit: $\mu \mathrm{m}$ ).

\begin{tabular}{lccc}
\hline Model & STD & MR & Error sum of squares \\
\hline Theory & 2.8 & 7.1 & 512 \\
Correction & 1.1 & 1.5 & 68 \\
\hline
\end{tabular}

As is shown in the figure, the corrected model enjoys higher prediction precision. The standard deviation is reduced by $39 \%$ and the maximum residual is reduced by $48 \%$.

According to the above experiments, the maximum residual and the standard derivation of the corrected model are $1.7 \mu \mathrm{m}$ and $1.1 \mu \mathrm{m}$, respectively, when the spindle velocity is $240 \mathrm{r} / \mathrm{min}$, indicating that the corrected model has high prediction precision and strong robustness. In the following section, the prediction results of the corrected model shall be verified at other velocities.

Maximum residual and standard deviation of the corrected model increased from $1.6 \mu \mathrm{m}$ to $2.1 \mu \mathrm{m}$ and from $1.0 \mu \mathrm{m}$ to $1.3 \mu \mathrm{m}$ separately at other velocities.

4.3. Prediction Range of the Corrected Model. To verify the effective prediction range of the corrected model, model (150r/min) was adopted to predict thermal deformation at $30 \mathrm{r} / \mathrm{min}, 60 \mathrm{r} / \mathrm{min}, 90 \mathrm{r} / \mathrm{min}, 120 \mathrm{r} / \mathrm{min}, 180 \mathrm{r} / \mathrm{min}, 210 \mathrm{r} / \mathrm{min}$, $240 \mathrm{r} / \mathrm{min}, 270 \mathrm{r} / \mathrm{min}$, and $300 \mathrm{r} / \mathrm{min}$, respectively. The prediction residuals are shown in Figure 15(a). Figure 15(b)
Table 6: Prediction results of $h$ (unit: $\mu \mathrm{m}$ ).

\begin{tabular}{lccc}
\hline Model & STD & MR & Error sum of squares \\
\hline Theory & 1.8 & 3.3 & 193 \\
Correction & 1.1 & 1.7 & 79 \\
\hline
\end{tabular}

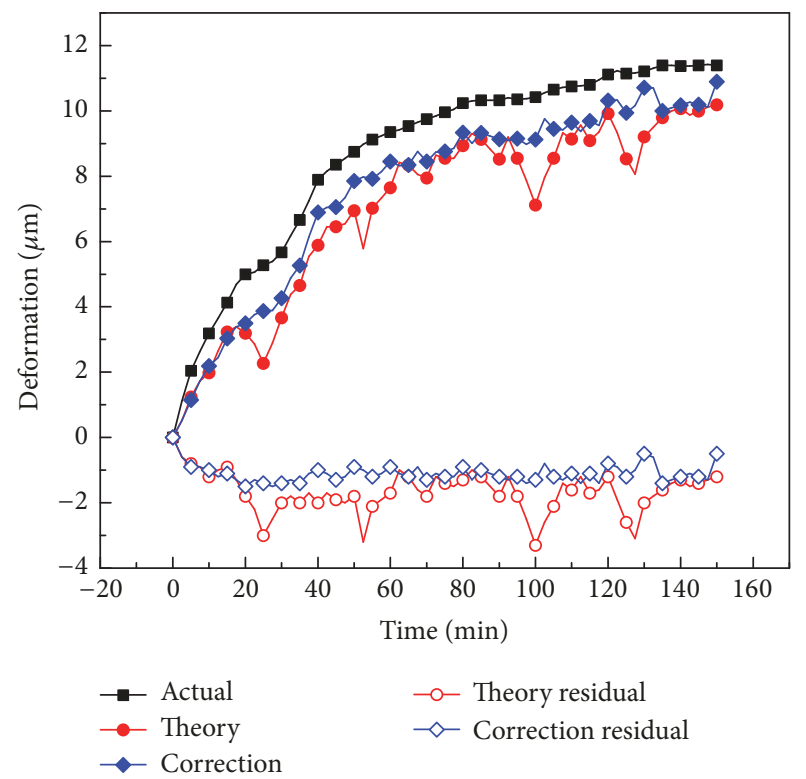

FIGURE 14: Comparison of $h$ before and after Correction.

demonstrates the profiles of the $\mathrm{X}$ axis and the $\mathrm{Y}$ axis in Figure 15(a). According to Figure 15, the prediction residual is small and the prediction precision is high when the corrected model predicts thermal errors at about $150 \mathrm{r} / \mathrm{min}$. The prediction residual is large when the rotational velocity is greater or smaller than $150 \mathrm{r} / \mathrm{m}$ (see $200 \mathrm{r} / \mathrm{min}$ and $50 \mathrm{r} / \mathrm{min}$ in Figure 15(b)). Therefore, the prediction precision decreases with the increase in prediction range when the prediction model has a definite prediction range. In addition, the prediction precision is higher when the prediction range is closer to the rotational velocity for modeling. Table 7 , which demonstrates the standard deviation and the maximum 


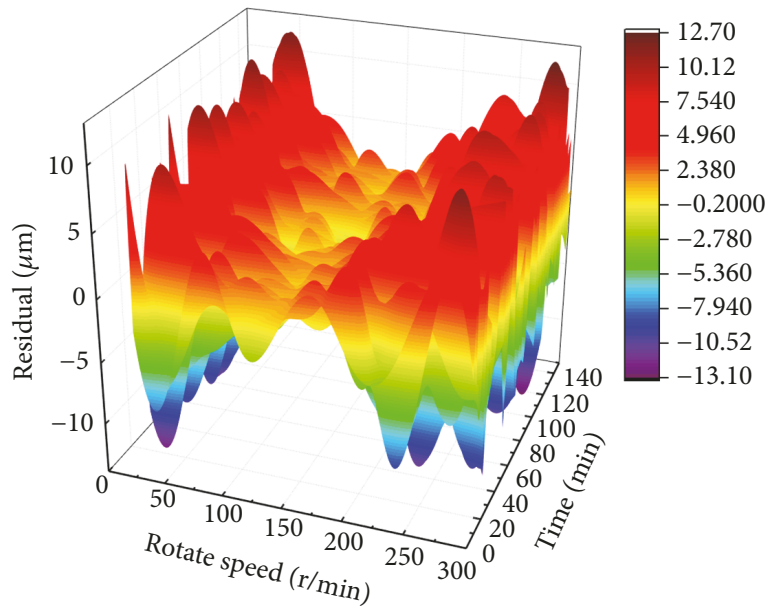

(a)

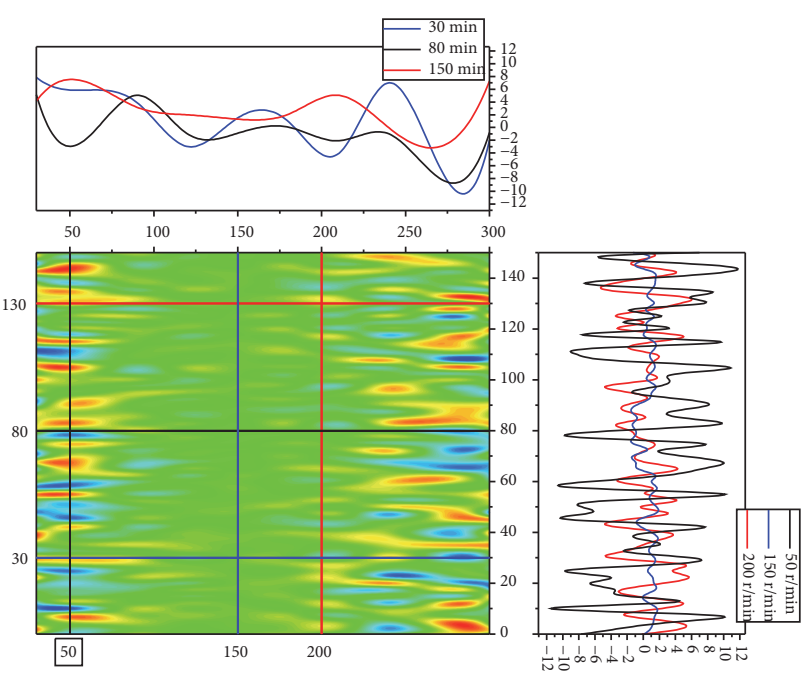

(b)

FIGURE 15: Error prediction result by model (150r/min): (a) residual result of 150r/min and (b) profile of X axis and Y axis.

TABLE 7: Prediction result by correction model (150r/min).

\begin{tabular}{lcc}
\hline Velocity $(\mathrm{r} / \mathrm{min})$ & STD $(\mu \mathrm{m})$ & $\mathrm{MR}(\mu \mathrm{m})$ \\
\hline 30 & 8.8 & -12.9 \\
60 & 6.7 & 10.7 \\
90 & 4.5 & -7.4 \\
120 & 1.3 & 2.3 \\
180 & 1.4 & 1.8 \\
210 & 4.6 & 6.5 \\
240 & 7 & 11.2 \\
270 & 8.6 & 12.5 \\
300 & 9.1 & -13.1 \\
\hline
\end{tabular}

residual at different rotational velocities, reveals the same laws as Figure 15.

To verify the above conclusions, model $(30 \mathrm{r} / \mathrm{min})$ and model $(300 \mathrm{r} / \mathrm{min})$ were adopted to predict $\Delta L$ at different velocities in Table 1. The results are shown in Figures 16 and 17 separately and consistent with the conclusions in Figure 15.

Since the prediction results on $h$ were consistent with those on $\triangle L$, the prediction range of $h$ was not repeatedly analyzed.

It can be concluded from the above analysis that the prediction model corrected based on temperature and thermal errors at a specific velocity has a specific prediction range. Therefore, the prediction range of the model should be limited to a specific range, so as to ensure the precision of the model proposed.

4.4. Classified Prediction of the Thermal Errors. To further improve the prediction precision of the corrected model, the prediction range at different rotational velocities was limited to modeling velocity $\pm 30 \mathrm{r} / \mathrm{min}$. Due to the impacts of machine tool assembly, lubrication, and other factors,

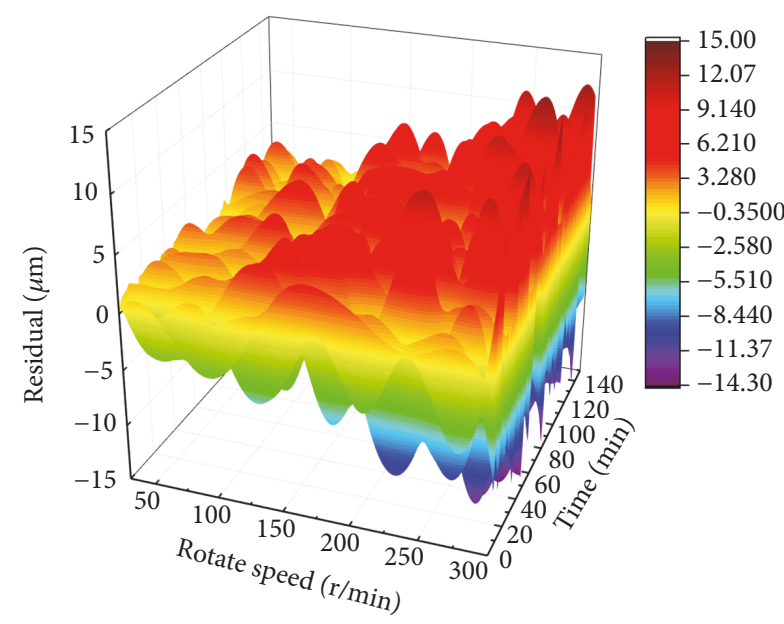

FIGURE 16: Thermal prediction result by model (30r/min).

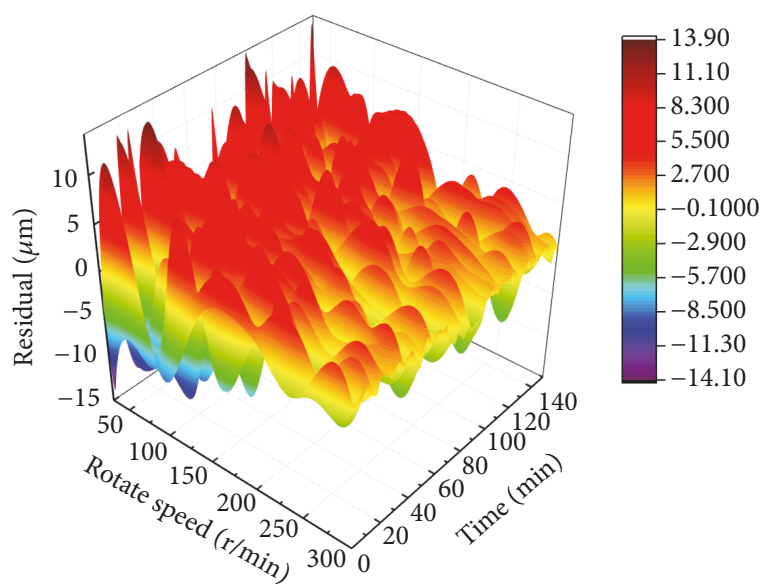

FIGURE 17: Thermal prediction result by model (300r/min). 
TABLE 8: Prediction result by model (90r/min).

\begin{tabular}{lcc}
\hline Velocity $(\mathrm{r} / \mathrm{min})$ & STD $(\mu \mathrm{m})$ & MR $(\mu \mathrm{m})$ \\
\hline 60 & 1.7 & 2.4 \\
70 & 1.5 & -2.3 \\
80 & 1.3 & 1.9 \\
100 & 1.4 & 1.9 \\
110 & 1.5 & -2.2 \\
120 & 1.6 & -2.5 \\
\hline
\end{tabular}

TABle 9: Prediction result by model (150r/min).

\begin{tabular}{lcc}
\hline Velocity $(\mathrm{r} / \mathrm{min})$ & STD $(\mu \mathrm{m})$ & $\mathrm{MR}(\mu \mathrm{m})$ \\
\hline 120 & 1.8 & 2.3 \\
130 & 1.7 & -1.9 \\
140 & 1.5 & 2 \\
160 & 1.3 & 1.7 \\
170 & 1.8 & -2.1 \\
180 & 2 & -2.5 \\
\hline
\end{tabular}

TABle 10: Prediction result by model (210r/min).

\begin{tabular}{lcc}
\hline Velocity $(\mathrm{r} / \mathrm{min})$ & STD $(\mu \mathrm{m})$ & $\mathrm{MR}(\mu \mathrm{m})$ \\
\hline 180 & 1.9 & -2.5 \\
190 & 1.8 & 2.3 \\
200 & 1.5 & -1.9 \\
220 & 1.5 & 2.1 \\
230 & 1.5 & -2.1 \\
240 & 1.9 & 2.5 \\
\hline
\end{tabular}

TABle 11: Prediction result by model (270r/min).

\begin{tabular}{lcc}
\hline Velocity $(\mathrm{r} / \mathrm{min})$ & STD $(\mu \mathrm{m})$ & MR $(\mu \mathrm{m})$ \\
\hline 240 & 1.6 & 2.5 \\
250 & 1.6 & 2.2 \\
260 & 1.3 & -2.0 \\
280 & 1.5 & 2.2 \\
290 & 1.7 & -2.3 \\
300 & 1.8 & -2.7 \\
\hline
\end{tabular}

thermal errors may be different. Therefore, verification experiments were carried out on another $\mathrm{CNC}$ gear grinding machine of the same type, so as to verify the robustness of the model.

Model (90r/min), model (150r/min), model (210r/min), and model $(270 \mathrm{r} / \mathrm{min})$ were employed to predict thermal errors in corresponding velocity ranges and the prediction results were shown in Tables 8, 9, 10, and 11 separately. As the tables show, the maximum standard deviation and the maximum residual are $1.9 \mu \mathrm{m}$ and $2.7 \mu \mathrm{m}$ separately when the prediction range is limited to modeling velocity $\pm 30 \mathrm{r} / \mathrm{min}$. Both prediction precision and robustness are high in that case.

\section{Conclusions}

(1) The sensorless prediction model effectively avoids the multicollinearity brought by improper measurement points and the poor robustness caused by sensor instability in traditional methods.

(2) The sensorless thermal error model can accurately predict thermal errors of the gear grinding machine selected. Standard deviation and maximum residual of the corrected model for $\triangle L$ are reduced by $60 \%$ and $79 \%$ separately, and those of the corrected model for $h$ are reduced by $39 \%$ and $48 \%$, respectively.

(3) Since prediction precision of the sensorless thermal error model decreases with the increase in prediction range, prediction precision of the model is effectively ensured by reasonably determining the prediction range and practicing classified prediction and compensation for thermal errors.

\section{Data Availability}

The data used to support the findings of this study are available from the corresponding author upon request.

\section{Conflicts of Interest}

The authors declare that they have no conflicts of interest.

\section{Acknowledgments}

This study is supported by the National Natural Science Foundation of China (no. 51375382), the Science and Technology Support Plan Project of Sichuan province, China (no. 2016GZ0205), Sichuan Key Research and Development Projects (no. 18FZ0089), and Key Laboratory Project of Shaanxi Education Department (no. 17JS095).

\section{References}

[1] J. B. Bryan, "International status of thermal error research," CIRP Annals - Manufacturing Technology, vol. 39, no. 2, pp. 645656, 1990.

[2] R. Ramesh, M. A. Mannan, and A. N. Poo, "Error compensation in machine tools- a review. Part II: Thermal errors," The International Journal of Machine Tools and Manufacture, vol. 40, no. 9, pp. 1257-1284, 2000.

[3] J. Mayr, J. Jedrzejewski, E. Uhlmann et al., "Thermal issues in machine tools," CIRP Annals - Manufacturing Technology, vol. 61, no. 2, pp. 771-791, 2012.

[4] S. Yang, J. Yuan, and J. Ni, "Accuracy enhancement of a horizontal machining center by real-time error compensation," Journal of Manufacturing Systems, vol. 15, no. 2, pp. 113-124, 1996.

[5] J. Yang, J. Yuan, and J. Ni, "Thermal error mode analysis and robust modeling for error compensation on a $\mathrm{CNC}$ turning center," The International Journal of Machine Tools and Manufacture, vol. 39, no. 9, pp. 1367-1381, 1999.

[6] J. Vyroubal, "Compensation of machine tool thermal deformation in spindle axis direction based on decomposition method," Precision Engineering, vol. 36, no. 1, pp. 121-127, 2012. 
[7] J.-H. Lee and S.-H. Yang, "Statistical optimization and assessment of a thermal error model for CNC machine tools," The International Journal of Machine Tools and Manufacture, vol. 42, no. 1, pp. 147-155, 2002.

[8] Q. Guo, R. Xu, T. Yang et al., "Application of GRAM and AFSACA-BPN to thermal error optimization modeling of CNC machine tools," The International Journal of Advanced Manufacturing Technology, vol. 83, no. 5-8, pp. 995-1002, 2016.

[9] X. Yao, J. Fu, Y. Xu, and Y. He, "Synthetic error modeling for NC machine tools based on intelligent technology," Procedia CIRP, vol. 10, pp. 91-97, 2013.

[10] X. Wei, F. Gao, Y. Li, Y. Li, and Z. Ma, “Optimization of thermal error model critical point for gantry machine tool feeding system," Yi Qi Yi Biao Xue Bao/Chinese Journal of Scientific Instrument, vol. 37, no. 6, pp. 1340-1346, 2016.

[11] E. Miao, Y. Liu, H. Liu, Z. Gao, and W. Li, "Study on the effects of changes in temperature-sensitive points on thermal error compensation model for CNC machine tool," The International Journal of Machine Tools and Manufacture, vol. 97, pp. 50-59, 2015.

[12] C. Zhang, F. Gao, Z. Meng, B. Zhao, and Y. Li, "A novel linear virtual temperature constructing method for thermal error modeling of machine tools," The International Journal of Advanced Manufacturing Technology, vol. 80, no. 9-12, pp. 19651973, 2015.

[13] M. Rudan, P. Ciampolini, M. Vecchi, A. Pierantoni, and L. Colalongo, "Sensor Modeling," Sensors Update, vol. 4, no. 1, pp. 109-137, 1998.

[14] J. Mayr, M. Ess, S. Weikert, and K. Wegener, "Simulation and prediction of the thermally induced deformations on machnie tools caused by moving linear axis using the fdem simulation approach," in Proceedings of the 23rd Annual Meeting of the American Society for Precision Engineering, ASPE 2008 and the 12th ICPE, October 2008.

[15] Z. Haitao, Y. Jianguo, and S. Jinhua, "Simulation of thermal behavior of a CNC machine tool spindle," The International Journal of Machine Tools and Manufacture, vol. 47, no. 6, pp. 1003-1010, 2007.

[16] E. Creighton, A. Honegger, A. Tulsian, and D. Mukhopadhyay, "Analysis of thermal errors in a high-speed micro-milling spindle," The International Journal of Machine Tools and Manufacture, vol. 50, no. 4, pp. 386-393, 2010.

[17] S. K. Kim and D. W. Cho, "Real-time estimation of temperature distribution in a ball-screw system," The International Journal of Machine Tools and Manufacture, vol. 37, no. 4, pp. 451-464, 1997.

[18] X. Min and X. Jiang, "A thermal model of a ball screw feed drive system for a machine tool," Proceedings of the Institution of Mechanical Engineers, Part C: Journal of Mechanical Engineering Science, vol. 225, no. 1, pp. 186-193, 2011.

[19] O. Horejs, "Thermo-Mechanical Model of Ball Screw With Non-Steady Heat Sources," in Proceedings of the 2007 International Conference on Thermal Issues in Emerging Technologies: Theory and Application, pp. 133-137, Cairo, Egypt, January 2007.

[20] Y. Li, W. Zhao, W. Wu, B. Lu, and Y. Chen, "Thermal error modeling of the spindle based on multiple variables for the precision machine tool," The International Journal of Advanced Manufacturing Technology, vol. 72, no. 9-12, pp. 1415-1427, 2014.

[21] B. Bossmanns and J. F. Tu, "A thermal model for high speed motorized spindles," The International Journal of Machine Tools and Manufacture, vol. 39, no. 9, pp. 1345-1366, 1999.

[22] H. Shi, C. Ma, J. Yang, L. Zhao, X. Mei, and G. Gong, "Investigation into effect of thermal expansion on thermally induced error of ball screw feed drive system of precision machine tools," The International Journal of Machine Tools and Manufacture, vol. 97, pp. 60-71, 2015.

[23] R. Ramesh, M. A. Mannan, and A. N. Poo, "Support vector machines model for classification of thermal error in machine tools," The International Journal of Advanced Manufacturing Technology, vol. 20, no. 2, pp. 114-120, 2002.

[24] T. Harris A, Rolling Bearing Analysis, Wiley Sons, New York, NY, USA, 1991.

[25] S. Xiang, J. Yang, and Y. Zhang, "Modeling method for spindle thermal error based on mechanism analysis and thermal basic characteristics tests," Jixie Gongcheng Xuebao/Journal of Mechanical Engineering, vol. 50, no. 11, pp. 144-152, 2014.

[26] Z. Chen, Thermal Characteristics Foundation of Machine Tools, Machinery Industry Press, Beijing, China, 1989.

[27] ISO 230-3, Test Code for Machine Tool - Part 3: Determination of Thermal Effects, ISO copyright office, Geneva, Switzerland, 2001. 


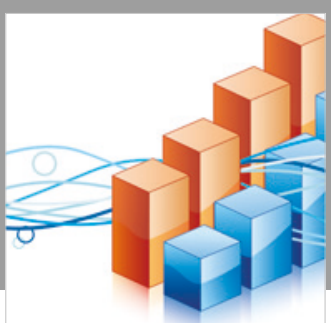

Advances in

Operations Research

\section{-n-m}
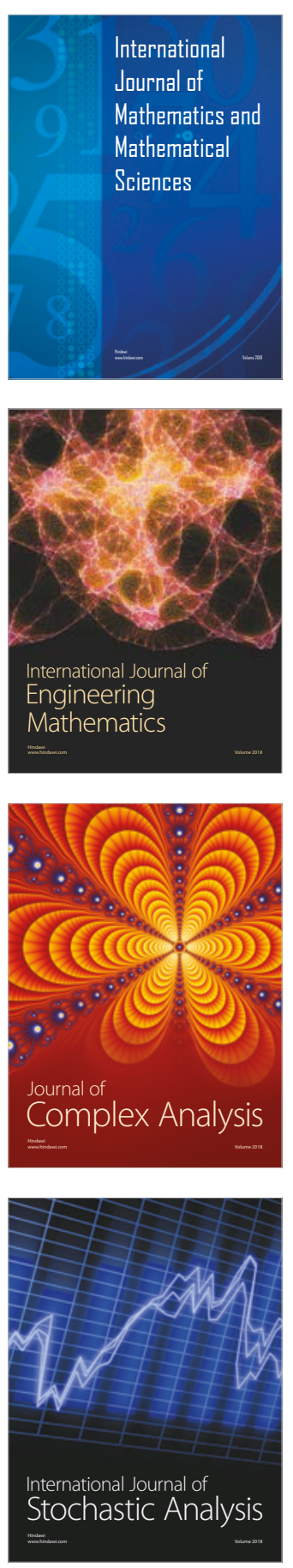
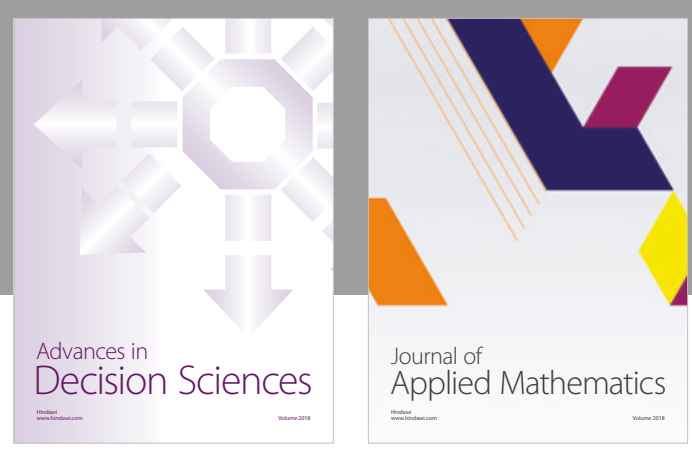

Journal of

Applied Mathematics
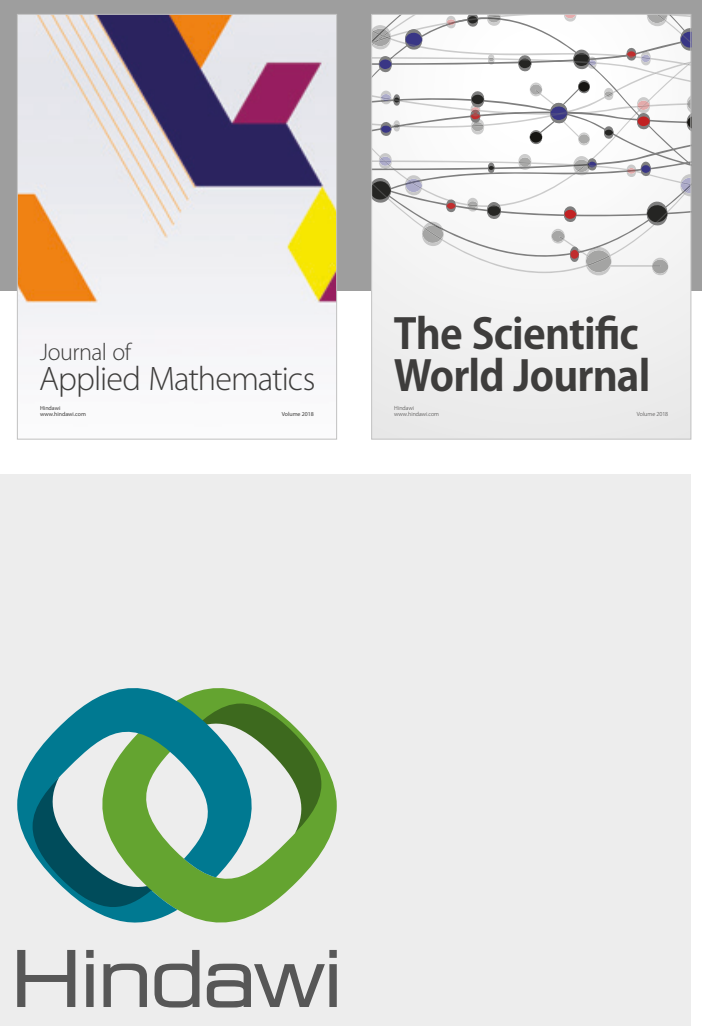

Submit your manuscripts at

www.hindawi.com

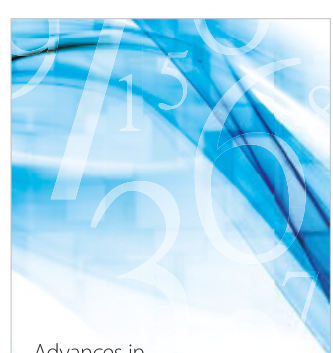

Advances in
Numerical Analysis
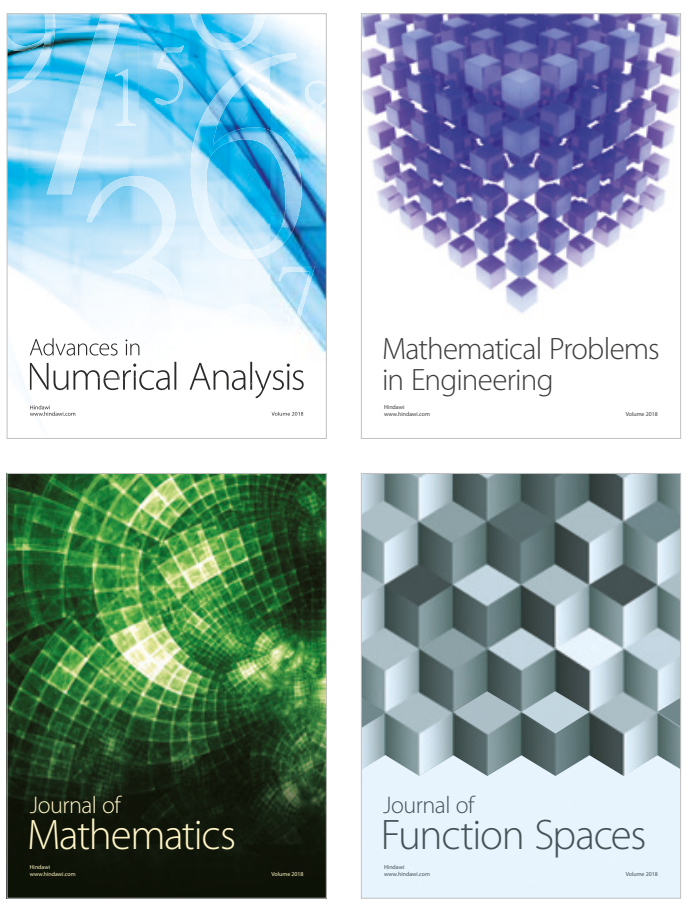

Mathematical Problems in Engineering

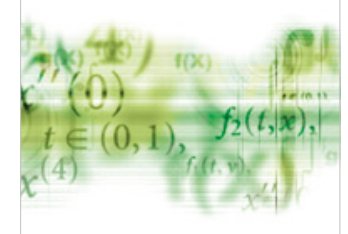

International Journal of

Differential Equations

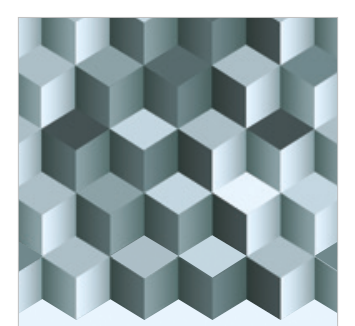

Journal of

Function Spaces

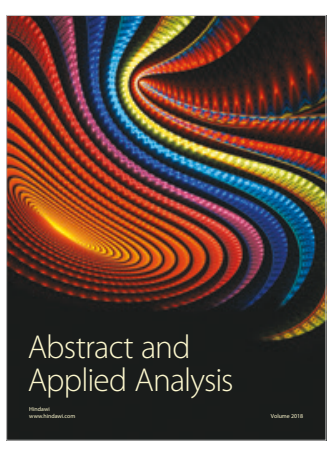

The Scientific

World Journal

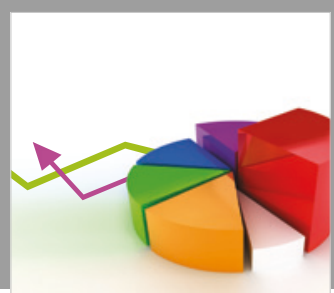

Journal of

Probability and Statistics
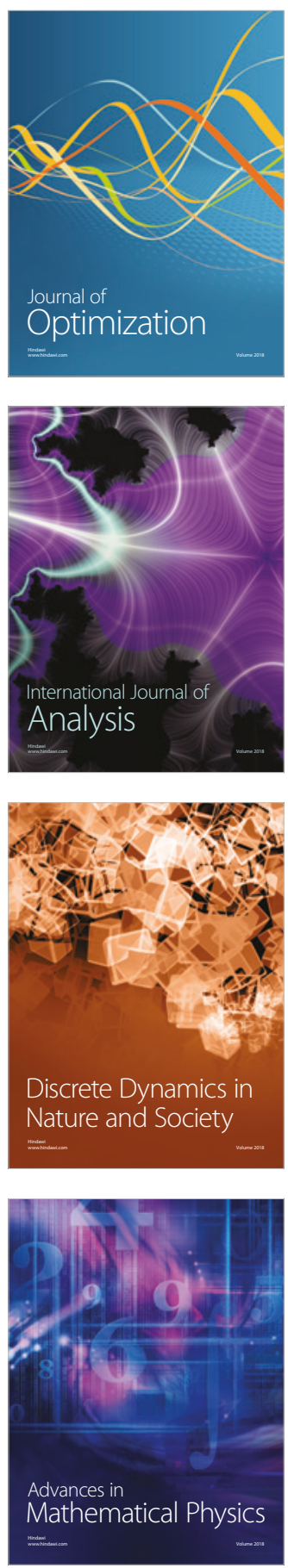